\section{Evaluating Animal Forage Preference ${ }^{1}$}

\author{
WILLIAM C. KRUEGER \\ Assistanl Professor, Rangeland Resources Program Oregon State \\ University, Corvallis.
}

\section{Highlight}

Four relative preference indices were used to rank sheep preference for twelve plant species in a tall-forb community of a summer range in southwestern Montana. Ranking of preference values for the plant species was different by all four indices. Frequency measurements of plant species both in the diet and on the range were found useful in interpreting forage preference. Diet frequency values measure consistency of intake while range frequency values measure plant distribution within a community. These values when incorporated into a relative preference index increase its sensitivity, but do not substitute for measurements of diet composition or forage availability on the rangeland studied.

Numerous factors influence prefence of grazing animals for individual plant species. Preference for any plant varies according to season of use, ecotypic differences, animal function, changes in plant community structure, and many other plant and animal modifiers. While the interactions of these preference modifying factors are important in determining which plant species a grazing animal will consume, most of them are not

\footnotetext{
${ }^{1}$ Received for publication October 7 , 1971.
}

suitable for inclusion as part of a relative preference index. Interpretation of preference index values should integrate numerical values with other influential factors not incorporated into the index. Absolute preference index values for a particular plant species may indicate whether that plant is preferred or rejected, but the primary value of preference indices is to rank various plants with regard to their palatability under a specified set of circumstances.

Bartlett (1958) rated palatability by the difference between utiliza- tion of a plant and average utilization of all plants on the range. Recognizing the influence of availability on forage preference, he computed the palatability index for high, medium, and low availability classes, which were examined independently. Van Dyne and Heady (1965) developed a relative preference index (RPI) which allowcd all availability classes to be considered simultaneously. Their index was a ratio of the percent of a plant in the diet to the percent availability of the plant. Chamrad and Box (1968) modified Van Dyne and Heady's index to include frequency of occurrence of a plant in the diet.

Diet frequency measurements can be important in determining relative preference of animals for specific plants because the index then includes not only the quantity of a plant the animals eat but also the consistency with which they select the plant. However, consistency of selection may be influenced by plant distribution, i.e., uniformly distributed plants might be more frequent in the diet than plants with irregular distribution. Allowance can be made for this by using frequency of the plant on the 
Table 1. Average RPI and relationship of frequency components for twelve plants studied.

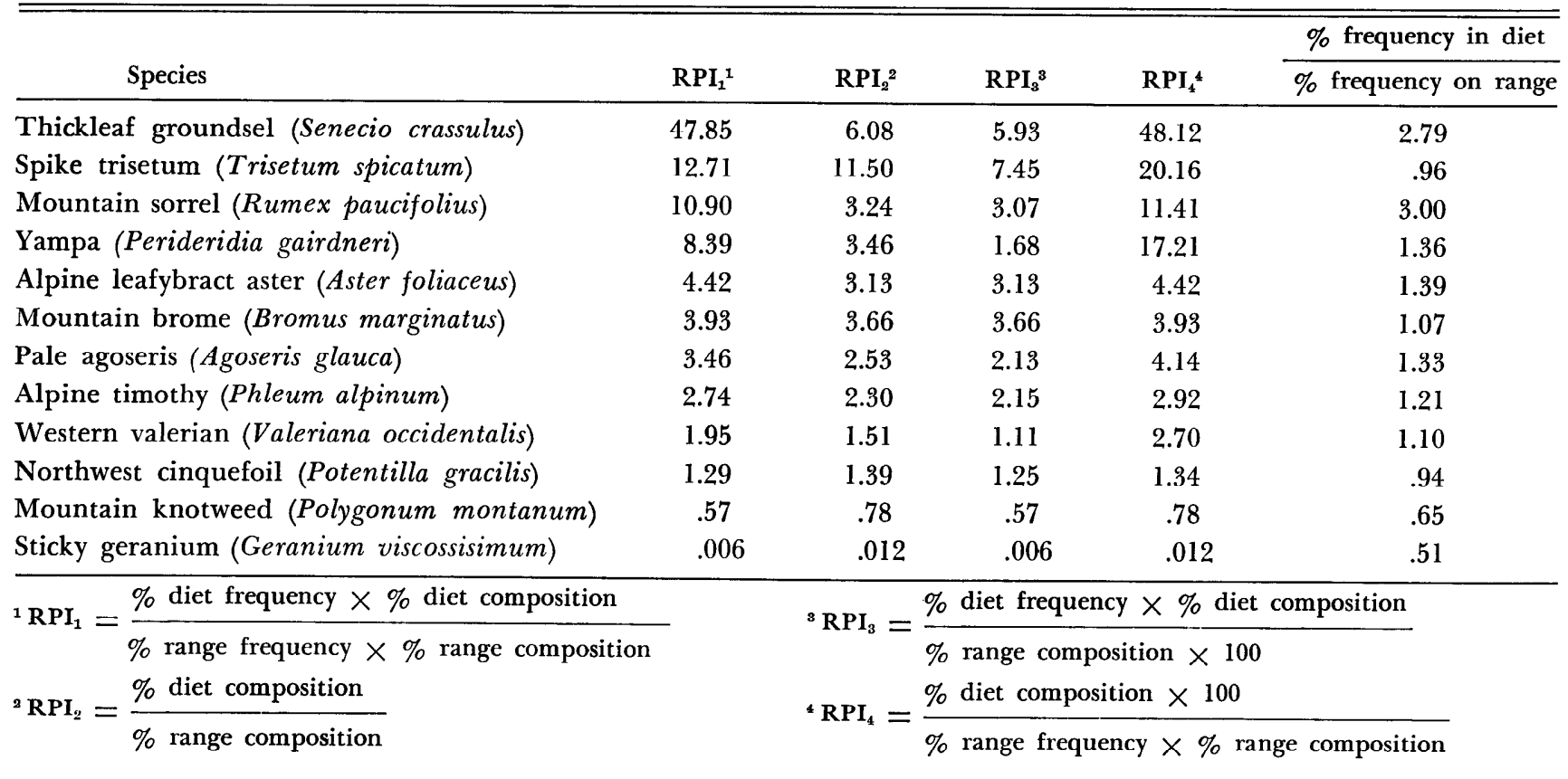

range as a part of the availability factor.

\section{Methods}

The study was conducted on the U.S. Sheep Experiment Station ${ }^{2}$ summer range in southwestern Montana within a tall-forb vegetation type. 'Two esophageally fistulated sheep per pasture were grazed in two separate 0.5 acre pastures. The fistulated sheep were used to collect forage samples for approximately one hour shortly after sunrise for five days during the early summer of 1968.

The fistula samples were analyzed by the microscopic point method under $15 \times$ magnification (Van Dyne and Hcady, 1965). Plants that could not be identified at this low power were mounted on slides with Hoyer's solution and identified with a compound microscope at $125 \times$ magnification (Ward, 1970). One hundred points were

\footnotetext{
${ }^{2}$ Cooperation by the Intermountain Forest and Range Experiment Station of the Forest Service, the Animal Husbandry Research Division of the Agricultural Research Service, U.S. Department of Agriculture, and the Idaho Agricultural Experiment Station is acknowledged.
}

examined for each sample to yield percent diet composition. The fistula collection from each sheep on each day was considered as one sample. Frequency in the diet for each plant species was determined as the percent of samples in which the species occurred.

Plant species within $30 \quad 4.8 \mathrm{ft}^{2}$ plots per pasture were clipped and weighed to give an estimate of the available green weight production. The weight of each plant species present in each pasture was divided by the total weight of forage produced in the pasture to yield percent range composition. Percent frequency on the range was computed for each plant species as the percentage of plots in which the species occurred.

Relative preferences for 12 plant species representative of varying levels of dietary composition were determined with four different indices.

$$
\begin{aligned}
\mathrm{RPI}_{1} & =\frac{\mathrm{fd} \times \mathrm{D}}{\mathrm{fr} \times \mathrm{R}} \\
\mathrm{RPI}_{2} & =\frac{\mathrm{D}}{\mathrm{R}} \\
\mathrm{RPI}_{3} & =\frac{\mathrm{fd} \times \mathrm{D}}{\mathrm{R} \times 100}
\end{aligned}
$$

$$
\mathrm{RPI}_{4}=\frac{\mathrm{D} \times 100}{\mathrm{fr} \times \mathrm{R}}
$$

where:

$$
\begin{aligned}
& \mathbf{f d}=\% \text { frequency in diet } \\
& \mathrm{D}=\% \text { diet composition } \\
& \mathrm{fr}=\% \text { frequency on range } \\
& \mathrm{R}=\% \text { range composition }
\end{aligned}
$$

All of the relative preference indices included the ratio of percent diet composition to percent range composition for each plant species. $\mathrm{RPI}_{1}$ included, in addition, the ratio of frequency in the diet to frequency on the range. No frequency measurements were used in $\mathrm{RPI}_{2}$. Both $\mathrm{RPI}_{3}$ and $\mathrm{RPI}_{4}$ included only one measure of frequency. $\mathrm{RPI}_{3}$ was a ratio of diet composition to range composition modified by frequency of the plant species in the diet, thus it accounted for the effects of consistency of selection but not for effects of plant species distribution within the community. $\mathrm{RPI}_{4}$ included the ratio of diet composition to range composition modificd by percent frequency on the range so it accounted for effects of plant species distribution but not consistency of selection. $\mathrm{RPI}_{3}$ and $\mathrm{RPI}_{4}$ both included constants in order to 
maintain the computed values of all four indices in the same order of magnitude.

The relative preference index values were computed for each sheep each day. Preference rankings for the plants were determined from overall average values. Each index was correlated with $\mathrm{RPI}_{1}$ to determine the linear relationship.

\section{Results}

The sheep in this study showed varying degrees of preference for different species of plants. Thickleaf groundsel (Senecio crassulus) was most preferred, according to $\mathrm{RPI}_{1}$ and $\mathrm{RPI}_{4}$ but not according to $\mathrm{RPI}_{2}$ or $\mathrm{RPI}_{3}$. Sticky geranium (Geranium viscossisimum) was least preferred of the twelve plants used to evaluate the different indices (Table 1). All plants except mountain knotweed (Polygonum montanum) and sticky geranium were preferred species, i.e., RPI $>$ 1.0. This was probably a result of high production of unpalatable geranium which made up $46 \%$ of the total production.

$\mathrm{RPI}_{4}$ more closely approximated $\mathrm{RPI}_{1}$ than the other indices. It showed a high correlation to $\mathrm{RPI}_{1}$ $(\mathrm{r}=.97)$. $\mathrm{RPI}_{2}$ and $\mathrm{RPI}_{3}$ were similar to each other but greatly different from $\mathrm{RPI}_{1}$. The correlation of $\mathrm{RPI}_{3}$ with $\mathrm{RPI}_{1}$ was low $(\mathrm{r}=.69)$ and $\mathrm{RPI}_{2}$ showed an even lower correlation with $\mathbf{R P I}_{1}$ $(\mathrm{r}=.51)$.

The relative ranking of animal preference for the twelve plants was different for all indices. $\mathrm{RPI}_{2}$ showed $50 \%$ agreement with $\mathrm{RPI}_{1}$. $\mathrm{RPI}_{3}$ agreed with $\mathrm{RPI}_{1}$ for $42 \%$ of the plants, and $\mathrm{RPI}_{4}$ ranked $67 \%$ of the plants in the same order as $\mathrm{RPI}_{1}$.

\section{Discussion}

The primary benefit received from calculating relative preference indices is comparison of prefence by animals for forage plants. Comparison of animal preference for different plant species is more meaningful if every plant has the same value when selection by animals is completely random. The
Table 2. Hypothetical plant community and expected diets for completely random animal selection. Species $A$ is irregularly distributed and species $B$ is uniformly distributed.

\begin{tabular}{ccccc}
\hline \hline $\begin{array}{c}\text { Plant } \\
\text { species }\end{array}$ & $\begin{array}{c}\text { Diet } \\
\text { composition } \\
(\%)\end{array}$ & $\begin{array}{c}\text { Frequency } \\
\text { in diet } \\
(\%)\end{array}$ & $\begin{array}{c}\text { Range } \\
\text { composition } \\
(\%)\end{array}$ & $\begin{array}{c}\text { Frequency } \\
\text { on range } \\
(\%)\end{array}$ \\
\hline A & 50 & 20 & 50 & 20 \\
B & 50 & 100 & 50 & 100 \\
\hline
\end{tabular}

index proposed by Van Dyne and Heady incorporating only diet and availability (range composition) and an index using frequency measurements for both diet and availability in conjunction with these factors meet this criterion. Indices using diet composition and range composition in combination with either frequency measurements of occurrence in the diet or occurrence on the range but not both, do not meet this criterion. For these indices, the value at completely random selection would vary for each plant species according to the frequency measurement used.

In order to illustrate the relationship of plant frequency on the range to the four relative preference indices examined, a hypothetical plant community was developed (Table 2). Plant species A comprised $50 \%$ of the total vegetation and was irregularly distributed. Species B also comprised $50 \%$ of the vegetation present and was uniformly distributed. If animals

grazed this community and forage selection was completely random, the diet composition and frequency values would be equal to the range composition and frequency values for each plant species. Using the information from this hypothetical situation, the four relative preference indices were computed for both plant species (Table 3). Indices using neither or both frequency values had a base value at random selection of 1.00 for both plant species. When the index incorporating frequency in the diet but not frequency on the range was used and the plants had an irregular distribution, the index base value at random selection was low. The index value would approach and then equal the value for indices with uniform range frequency at completely random selection (1.00) as diet frequency approaches and then equals $100 \%$. Conversely, when the index incorporating frequency on the range but not frequency in the diet was used, the base value at random

Table 3. Relative preference indices for an irregularly distributed plant (species $\mathbf{A}$ ) and a uniformly distributed plant (species B) when animal selection is completely random.

\begin{tabular}{ccccc}
\hline $\begin{array}{c}\text { Plant } \\
\text { species }\end{array}$ & $\mathbf{R P I}_{1}{ }^{1}$ & $\mathbf{R P I}_{2}{ }^{2}$ & $\mathbf{R P I}^{3}$ & $\mathbf{R P I}{ }^{4}$ \\
\hline $\mathrm{A}$ & 1.00 & 1.00 & .20 & 5.00 \\
$\mathrm{~B}$ & 1.00 & 1.00 & 1.00 & 1.00 \\
\hline
\end{tabular}

$$
\begin{aligned}
{ }^{1} \mathrm{RPI}_{1} & =\frac{\% \text { diet frequency } \times \% \text { diet composition }}{\% \text { range frequency } \times \% \text { range composition }} \\
{ }^{2} \mathrm{RPI}_{2} & =\frac{\% \text { diet composition }}{\% \text { range composition }} \\
{ }^{3} \mathrm{RPI}_{3} & =\frac{\% \text { diet frequency } \times \% \text { diet composition }}{\% \text { range composition } \times 100} \\
{ }^{4} \mathrm{RPI}_{4} & =\frac{\% \text { diet composition } \times 100}{\% \text { range frequency } \times \% \text { range composition }}
\end{aligned}
$$


selection for scattered plants was high. This index value would dccrease to the value for the plants with uniform distribution (1.00) as range frequency increases to $100 \%$.

Frequency measurements can be useful in determining relative preference of sheep. Since consistency of selection and distribution of plants are related to animal preference, an index incorporating both of these factors $\left(\mathrm{RPI}_{1}\right)$ is more sensitive in ranking preference values compared to indices lacking one or both of these factors. It was decided $\mathrm{RPI}_{1}$ was the most useful index because it has the same value for all plant species when selection is completely random (1.00); it provides a wider spread of values than the indices not incorporating range frequency, so preference differences are more obvious; and it considers more factors related to preference than the other indices.

Frequency measurements are dependent on plot size. As the size of a plot increases the frequency of occurrence of a plant species would be expected to increase. If plot sizes are equal, comparison of frequency values is straight forward. If plot sizes are unequal, comparison of frequency values becomes more complex. To facilitate the use of range frequency data a plot size should be selected that provides a fairly wide range in values so differences in distribution of various plant species can be identified. In this study percent frequency on the range of the twelve plant species studied ranged from 22 to $100 \%$.

Diet frequency values are a measure of consistency of selection. These values are primarily dependent on distribution of the various plant species on the range and animal preference. While a sheep is grazing it will morc frequently cncounter the plants with more uniform distribution and less frequently encounter plants with an irregular distribution. So, if precent frequency on the range is $20 \%$ for a particular plant species a sheep would find and be able to graze that plant one-fifth as often as a plant with $100 \%$ range frequency. Consequently, the range in values for percent frequency in the diet would be expected to be modified by percent frequency of species within a plant community and according to the relative palatability of the various plant species. Length of time spent grazing can also influence the frequency of a plant species in the diet. Enough time should be allowed so the fistulated animals can adequately cover the area to be sampled, but short enough so frequency differences can be identified. The number of microscopic points examined per sample will also influence the diet frequency value. As more points are examined the possibility of recording a very sparse plant in the sample increases. This influence can be minimized by setting a lower limit on values to be included in the frequency calculation, e.g., any plant making up less than $1 \%$ of the composition could be recorded as absent in determining frequency in the diet. In this study the range of diet frequency values was 30 to $100 \%$, with most of the values above $60 \%$.

In theory, the ratio of percent frequency of a plant in the diet and percent frequency on the range should give some insight into the animal's preference for the plant. If the ratio is less than one it would indicate the animal rejected the plant when it was encountered on the range. If the value is very close to one it would indicate the animal consumed some of the plant whenever the animal discovered its presence. If the ratio is greater than one it would indicate the animal was actively seeking the plant and thus enhancing the possibility of grazing preferred vegetation.

Because of the dependency of frequency measurements on plot size and time spent grazing, it is difficult to interpret the ratio of diet and range frequency from field data. However, if it is as- sumed that the proper plot size was selected and frequency measurements of the range and diet are satisfactory, then comparisons of the two different frequency measurements can be considered. In this study the ratio of the frequency measurements tended to decline as preference for the different plants declined (Table 1). Plants that were highly preferred had a high ratio and plants that were rejected had a ratio value much less than one.

Spike trisetum (Trisetum spicatum) was evaluated as highly preferred by all of the relative preference indices used, yet, the ratio of frequency measurements was almost one. Based on the frequency ratios for other plant species, the value for spike trisetum indicated it should have been of low to moderate palatability. But, as previously indicated, preference is not based on frequency of selection and distribution alone. The amount of the plant consumed in relation to the amount available must also be considered. In the case of spike trisetum, frequency measurements added little to preference evaluation. The animals apparently did not seek it out but did consume a large proportion of the plant when it was encountered. Thus, it appeared that animal preference for different plant species was related to composition of intake and availability as well as frequency of intake and plant distribution.

The four preference indices were computed for twelve representative plant species and then compared with $\mathrm{RPI}_{1}$ which was accepted as the standard evaluation. The index that did not incorporate any frequency measurements $\left(\mathrm{RPI}_{2}\right)$ did have a constant value for all plant species when selection was completely random (Table 3) but did not have as wide a spread of index values as $\mathrm{RPI}_{1}$ (Table 1 ) and did not consider the effects of plant distribution or consistency of intake. This index had the lowest correlation with $\mathrm{RPI}_{1}$ and ranked 
the plant species in the same order as $\mathrm{RPI}_{1}$ only $50 \%$ of the time. Because of the low level of agreement of these two indices and difference in sensitivity $\mathrm{RPI}_{2}$ was considered to be less useful.

The index incorporating diet frequency but not range frequency $\left(\mathrm{RPI}_{3}\right)$ did not have a constant value when selection was completely random, it did not have as wide a spread of index values as $\mathrm{RPI}_{1}$, and did not consider the effects of plant distribution. This index ranked the preference values the same as RPI $\mathbf{I}_{1}$ least frequently of the indices studied and showed a low correlation with $\mathrm{RPI}_{1}$. When ranking preference values for unpalatable plants, $\mathrm{RPI}_{3}$ values were the same as those of $\mathrm{RPI}_{1}$, but in these cases range frequency equaled $100 \%$, so mathematically the indices were identical. It appeared the addition of diet frequency measurements alone added very little to the usefulness of the index.

The index using range frequency measurements but not diet frequency did not have a constant value when selection was completely random, it did provide as wide a spread of index values as $\mathrm{RPI}_{1}$, but did not consider the effects of consistency of intake. This index $\left(\mathrm{RPI}_{4}\right)$ agreed most frequently with $\mathrm{RPI}_{\mathbf{1}}$ in ranking pref- erence values for plants and had a high correlation with $\mathrm{RPI}_{1}$. The preference index values for $\mathrm{RPI}_{4}$ and $\mathrm{RPI}_{1}$ were very similar. $\mathrm{RPI}_{4}$ tended to rate plants higher as in the model (Table 3) and agreed with $\mathrm{RPI}_{1}$ when dict frequency equaled $100 \%$. If diet frequency measurements cannot be obtained, as in determining diet from utilization and production estimates, $\mathrm{RPI}_{4}$ can be a satisfactory substitute for $\mathrm{RPI}_{1}$ on this range.

\section{Summary and Conclusions}

Four different relative preference indices were compared and the contribution of frequency measurements was evaluated. The preference indices incorporating both frequency of occurrence in the diet and on the range or neither frequency measurement had the same base value for all plants when selection was completely random, while preference indices using either diet or range frequency, but not both, did not have a common base value. The index that included diet and range composition and diet and range frequency not only had a common base value at random selection but also more clearly showed preference differences than indices not using range frequency and considered more factors related to preference than the other indices, so it was considered to be the most useful of the four relative preference indices studied.

While frequency ratios do provide added information concerning animal preference for most plants, they are not a satisfactory substitute for composition measurements of the diet and available forage. For some plant species frequcncy measurements would not be expected to modify preference values and for other plant species frequency measurements may raise or lower preference values, as determined from composition ratios.

\section{Literature Cited}

Bartlett, C. O. 1958. A study of some deer and forest relationships in Rondeau Provincial Park. Ont. Dep. of Lands and Forest. Wildlife Series No. 7. 172 p.

Chamrad, A. D., and T. W. Box. 1968. Food habits of white-tailed deer in South Texas. J. Range Manage. 21:158-164.

Van Dyne, G. M., and H. F. Heady. 1965. Botanical composition of sheep and cattle diets on a mature annual range. Hilgardia 36:465492.

WARD, A. L. 1970. Stomach content and fccal analysis: Methods of forage identification. 146-158. In: Range and wildlife habitat evaluation-a research symposium. U.S. Forest Serv. Misc. Publ. 1147. 220 p. 